\title{
Employability, Community Engagement, and Global Citizenship: The New Face of Universities
}

\author{
Maria Florencia Amigó \\ \{maria.amigo@mq.edu.au\}
}

Professional and Community, Engagement, Macquarie University Australia, Sydney, Australia

\begin{abstract}
The higher education sector is facing an unprecedented context which is challenging its identity, raison d'etre, and sustainability. Knowledge is now more accessible than ever before, and practical experience, adaptability, and digital literacy weigh more than degrees in the face of employers. In these circumstances, how are universities transforming themselves to remain relevant, necessary and sustainable? This question begs a multi-pronged analysis of the changing nature and role of higher education institutions. In this paper, I propose to shed light on the myriad challenges universities are facing and discuss how a combination of pedagogical, operational and community engagement strategies can radically transform the nature of higher education in order for it to flourish. I will discuss how universities' role is to prepare future generations of ethically engaged, soft skills-equipped individuals, who invest in university education to develop a critical and meaningful understanding of a changing world, become life-long learners, and experience - not just read about - the relevance of the disciplines they are studying. I will suggest that universities need to shift their purpose from being knowledge generators and knowledge disseminators to becoming knowledge convenors that commit to working with the communities around them.
\end{abstract}

Keywords: higher education, employability, future of work, community engagement.

\section{Introduction}

In the last couple of decades, and becoming each time more prominent, there have been powerful discussions around the future of work, the precarious environments that are foreseeable at the moment, and the role of higher education in taking on the responsibility to produce graduates that will be not only ready for that future, but more importantly, in demand. In many contexts, higher education institutions are now the liaison between students and employers, and many of their staff, both academic and professionals are faced with the pressure to provide knowledge, skills, and direction for the future workers within their classrooms. The pressure may not just come from students themselves, but also parents, employers and the community at large. Universities are now embedded in very dynamic and ever-changing contexts.

Themes of precarity, risk and individualization map strongly onto the graduate transition from university to the labor market [1]. The higher education sector is at the forefront of these changing labor markets. Precarious work environments have changed the nature of funding regimes, who is attending university and how students conceive of the relationship between the university and their work lives. In this environment, the employability of students has emerged as a key concern of universities. 
On the other side, the way knowledge is now generated, disseminated and legitimised, for example falls now beyond the domain of universities. Rapidly changing pedagogies, digitalisation of learning and teaching, and innovative ways of conducting research such as citizen science and collaborative partnerships with industry means the boundaries between universities and communities regarding knowledge generation are increasingly blurred [2]. On the other side, a degree is not a guarantee of employment, and when the cost of higher education is increasing, but at the same time more young people are affording higher education, universities are under pressure to adjust, change and deliver.

The questions this paper wants to expose are: how are universities transforming themselves to remain relevant, necessary and sustainable? What is the new role of universities? Moreover, how are universities incorporating technology to manage and disseminate knowledge?

\section{An Alarmist Scenario?}

Despite the tone of alarm in accounts of the future of higher education and the future of work this article wants to explore the potentialities and opportunities of this reality rather than reinforce the glooming and alarmist scenario made ever more present by the media, but by higher education institutions themselves, which are constantly reminding their students of the constant need to adjust to be fit to face a reality of constant upskilling, increasing reliance on technology, several careers over a lifetime, precariety of work, and the increasingly global nature of workplaces [3] Young people are naturally feeling anxious about the future, and many have started to wonder where the value of higher education lies. The pressure for students to constantly adapt to an unpredictable future, market themselves in the most effective ways, to have an advantage in the ever more competitive labor market.

The purpose of this paper is to deconstruct the discourses that are presenting this alarmist scenario and offer an alternative yet critical discourse on education, employment, and employability that can offer hope and reassurance rather than anxiety. This paper wants to suggest that despite the challenges, universities now face incredible opportunities to make a difference in the lives of the student population they serve, but also regarding their contribution to positive social change. At no historical point have universities been more accessible than they are today, with increasing numbers of students, inclusive policies to encourage enrolments from disadvantaged sectors, and expanding connections with communities, industry, and government. Alongside these factors, the digitalisation of learning is offering innovative possibilities for students, teachers, and external stakeholders to connect and collaborate. So despite the alarmist scenario that suggests that higher education may have become obsolete [4], and the future of work uncertain and worrying [5], in many parts of the world universities are taking the lead to occupy a space they haven't before: they are becoming the key nexus between education and employment, social and environmental issues and research to find applied solutions, and community development facilitators. 


\section{Experiential and Work Integrated Learning}

Under these circumstances the opportunities to revolutionise higher education are unprecedented. The closer connection with, and the need universities have to engage with external stakeholders have open up opportunities for students to benefit from applying knowledge to practical situations and learning on the job while involved in work integrated learning, which is now a core component of many degrees. These connections between studies and learning by doing through the involvement of external stakeholders further strengthens the relationships between academia and industry, leading in many cases to research collaborations.

Experiential learning and work-integrated learning, where students engage with industry, community and government to translate their academic knowledge into practice, not only provide a way to maximise students' time at university in terms of acquiring capital that will link directly to their professional lives beyond university, but is also a vehicle for them to reflect on the future of work, and develop soft skills valued by industry, such as decision making, team work and initiative, as well as develop networks. Many universities are also taking this opportunity to introduce in the normative curriculum content such as ethical engagement and global citizenship, and engaging with partner organisations in reciprocal ways to mutually benefit from each other, even co-create curriculum [6].

In countries such as Australia these developments in terms of experiential and workintegrated learning have derived in a re-structuration of traditional learning and teaching social relations, where students learn on site, are requested to focus on soft and transferable skills, become entrepreneurs and life-long learners. University teachers, on the other side, are constantly pushed to innovate, incorporate digital pedagogies and engage with industry and communities in new ways. On the other side, external partners that host students and engage in learning and teaching relationships themselves, find the need to understand better the parameters governing education, employment, and the university-community engagement. With the pressure for universities to deliver work-ready graduates, also as part of the imperative to compete with other providers, traditional ways of delivering and receiving an education have been disrupted, and even the sole purpose of university education, and the identities of those involved in it are being redefined.

\section{A Critical Approach}

The pressures for universities to reinvent themselves have not gone without criticisms. The ascendancy of neoliberalism and the associated discourses of 'new public management', during the 1980s and 1990s has produced a fundamental shift in the way universities endeavour to measure and quantify their impact [7].

As a consequence, the rhetorical focus on employability has been critiqued as one part of a broader neoliberal push to economise, financialize and corporatize the public university [8] . Simultaneously, there has been an enhancement of a more critical approach to university engagement. This approach emphasizes that the university is a site of public good that has a normative role to play invigorating civic engagement and being a site of social transformation. The employability and public good perspectives complement and sit in tension with one another, and this critical approach emphasizes a higher education process that Beck and BeckGermsheim have referred to as 'institutionalised individualisation' [9]. In this process, the burden is on the individual to deal with the risks and responsibilities associated with 
employment, which also has implications for the individualization of learning, with increasing pressure for university students to self-curate employable skills. As an example, a recent government report in Australia has reiterated that adaptability, innovation, and life-long critique of self and career have become key to achieving sustained employment for graduates [10].

In this discourse a critique of the expansion and some cases compulsory nature of experiential and work integrated learning as part of university programs have also emerged. Zemblyas for example, highlights how an individual's subjectivity is shaped through learning in the context of the workplace. This author argues that these modalities of working, learning and teaching may imply new governmentality (using Foucault's terminology), where new systems of knowledge, research and practice are dependent on self-regulating professionals. In his view education institutions that are aligned with these modalities are more commercial rather than educational, and "work" shapes the curriculum to be learned. In this sense, work integrated learning as endorsed by universities, creates an opportunity for organisations to mold individuals whose personal objectives merge with those of the organisation [11].

These critiques play an important role in appraising the deep transformations universities are undergoing, and considering how the renewed practices, identities, and ideologies that emerge are responding to a future that is uncertain, but where the precariety of work takes a central place in the imaginary of students, teachers and employers alike.

\section{Where to Next?}

What is missing from this discussion is a reference to transnational education and student flows. The globalised nature of the economy and education also has implications for how and where universities 'engage' with the world. Universities are transnational spaces, they are included in, but they also go beyond the local labour market and for this reason, the impact of global discourses of employability, entrepreneurship and engagement should also be accounted for. There is a complex and at the same time hopeful connection between higher education, employability, precarious work environments, work integrated learning, external engagement, digital technologies and transnational forces. There is potential for universities to become agents of positive social transformation. The challenge is how they can remain as spaces of intellectual advancement, academic freedom, and critical thinking, while at the same time being responsive to the needs and concerns of a generation that will face a precarious and disrupted world of work, but where digitalisation opens up new opportunities for people to learn, connect and work. At the same time, universities are being called to engage with real world problems and provide solutions. This presents an unprecedented opportunity for teachers, researchers, students, communities, government, and industry, to teach, learn, research, consult, practice, and collaborate in similarly disruptive (but constructive) ways.

\section{References}

[1] Southwood, I. Against Precarity, Against Employability. In E. Armano, A. Bove, \& A. Murgia (Eds.), Mapping Precariousness, Labour Insecurity and Uncertain Livelihoods. London: Routledge, 2016 Retrieved from https://www-taylorfranciscom.ezproxy1.library.usyd.edu.au/books/e/9781317100843/chapters/10.4324\%2F9781315593 838-12

[2] Siemens, G. Knowing knowledge. Lulu.com. 2006. 
[3] Styhre, A. Precarious Professional Work: Entrepreneurialism, Risk and Economic Compensation in the Knowledge Economy. Sweden: Palgrave Macmillan, 2017.

[4] Arvanitakis, James, \& David J. Hornsby. "Are Universities Redundant?" in Universities, the citizen scholar and the future of higher education. Palgrave Macmillan UK, 2016 pp 7-20.

[5] Dunlop, T. Why the Future is workless. NewSouth Press, Sydney, 2016.

[6] Bilous, R., Hammersley, L.A., Lloyd, K., Rawlings-Sanaei, F., Downey, G., Amigo, M., Gilchrist, S. \& Baker, M.. 'All of us together in a blurred space': principles for co-creating curriculum with international partners, International Journal for Academic Development, 2018.

[7] Olssen, M., \& Peters, M. A. Neoliberalism, Higher education and the knowledge economy: from the free market to knowledge capitalism. Journal of Education Policy, 20(3), 2000, pp 313-345. https://doi.org/10.1080/02680930500108718

[8] Armano, E., Bove, A., \& Murgia, A. (Eds.). Mapping Precariousness, Labour Insecurity, and Uncertain Livelihoods. London: Routledge, 2017.

[9] Beck, U., \& Beck-Gernsheim, E. Individualization: Institutionalized Individualism and its Social and Political Consequences. London, 2002. https://doi.org/10.4135/9781446218693

[10] Bennett, D., Richardson, S., \& MacKinnon, P. Enacting Strategies for Graduate Employability: How Universities can Best Support Students to Develop Generic Skill. (Australian Government Office for Learning and Teaching No. Part A). Canberra, ACT: Department of Education and Training, 2016.

[11] Garrick, J., \& Usher, R. Flexible learning, contemporary work and enterprising selves. Electronic journal of sociology 5(1), 2000 pp 1-15. 